\title{
HILIRISASI TEKNIK HANDLING IKAN MAS HIDUP SISTEM KERING KEPADA MASYARAKAT PERIKANAN DI PEDESAAN
}

\author{
I Ketut Suwetja ${ }^{1}$, Jenki Pongoh ${ }^{1}$, I Gede Prabawa Suwetja ${ }^{2}$ \\ ${ }^{1)}$ Staf pengajar pada Program Studi Teknologi Hasil Perikanan FPIK Unsrat Manado \\ ${ }^{2)}$ Staf pengajar pada Fakultas Ekonomi dan Bisnis Unsrat Manado \\ Email: suwetja.i.k@gmail.com
}

\begin{abstract}
ABSTRAK
Penyuluhan, pelatihan, pendampingan dan evaluasi teknik handling ikan mas hidup sistem kering kepada masyarakat perikanan di pedesaan telah dilakukan teknik pemingsanan yang diaplikasikan ialah dengan suhu $8^{\circ} \mathrm{C}$ dan $8^{\circ} \mathrm{C}+0,02 \%$ minyak cengkih. Dilanjutkan dengan penyimpanan dilakukan pada media sekam padi dingin dengan suhu $10-15^{\circ} \mathrm{C}$. Pekerjaan selanjutnya ialah penyadaran ikan. Ikan disadarkan pada air habitat dilengkapi dengan aerator kapasitas 3 volt dan kemudian dilanjutkan dengan menghitung tingkat mortalitas ikan.
\end{abstract}

Kata kunci: Hilirisasi, teknik handling, system kering, aerator, sekam padi, mortalitas.

\section{PENDAHULUAN}

Penyuluhan, pelatihan, pendampingan dan evaluasi teknik handling ikan mas hidup sistem kering kepada masyarakat perikanan di pedesaan telah dilakukan. Pengangkutan ikan hidup di Indonesia umumnya dilakukan dengan cara mengemas ikan dalam suatu wadah tertentu seperti kantong plastik yang diisi air, kemudian ada yang ditambahkan oksigen dan ada juga tidak, tergantung pada kebutuhannya. Cara pengemasan dan pengangkutan ikan hidup seperti itu memiliki banyak kekurangan, antara lain: kurang efisien dari segi berat, volume dan biaya pengangkutan; kadar oksigen di dalam air berkurang, suhu air meningkat, kotoran ikan dapat meracuni ikan dan waktu pengangkutan yang relatif lama.

Telah dikembangkan suatu usaha pengangkutan ikan hidup tanpa media air yaitu dengan metode pemingsanan dengan menggunakan suhu rendah. Metode ini dilakukan dengan mendinginkan air sampai suhu pingsan ikan. Kemudian, untuk mempertahankan suhu tetap rendah digunakan wadah kotak Styrofoam yang diisi es secukupnya. Media dingin untuk penyimpanan ikan digunakan sekam padi atau serbuk gergaji.

Ikan mas hidup yang dipingsankan dengan suhu rendah dan disimpan dalam media dingin tanpa air mampu bertahan hidup selama 6-7 jam pemingsanan dengan suhu penyimpanan $10-15^{\circ} \mathrm{C}$. (Suwetja $d k k, 1993$ ). Dosis yang baik untuk pemingsanan ikan dengan minyak cengkih berkisar $1-5 \mathrm{ml} / 101$ air. Penggunaan minyak cengkih berlebihan dapat menyebabkan kematian ikan. Pemingsanan ikan dengan minyak cengkih dilakukan dengan cara memasukkan ikan hidup ke dalam air yang sudah dicampur minyak cengkih.

Agar mulut dan insang ikan tidak kemasukkan media maka sebelum disimpan ikan terlebih dahulu dikemas dengan kertas (Suwetja $d k k, 1993$ ). Ikan yang telah dibungkus kemudian ditidurkan dan disusun dalam kotak styrofoam berisi serbuk gergaji dingin yang bersuhu $10-15^{\circ} \mathrm{C}$ selanjutnya penyusunan ikan dilakukan secara berlapis-lapis yaitu media, ikan, media dan seterusnya hingga lapisan teratasnya adalah media. Ketebalan lapisan media ini kurang lebih 2-3 cm.Agar suhu tetap stabil, ke dalam kotak diisikan es (Suwetja dan Pongoh, 2000).

Untuk menyadarkan ikan mas setelah dipingsankan dapat dilakukan dengan cara mengembalikan ikan pada suhu habitatnya $\left(25-27^{\circ} \mathrm{C}\right)$ dalam bak penampung serta diberi aerasi secukupnya. Daya tahan ikan hidup yang dikemas dalam kondisi pingsan dipengaruhi oleh kondis awal ikan, suhu pemingsanan, asal ikan, serta guncangan yang dapat menyebabkan tertindihnya ikan pada lapisan dasar dan dapat menyebabkan kematian selama transportasi (Suwetja dkk, 2012). 


\section{METODE PELAKSANAAN}

Sebagai media pemingsanan digunakan suhu rendah $8^{\circ} \mathrm{C}$, dan suhu rendah $8^{\circ} \mathrm{C}$ yang ditambahkan dengan $0,02 \%$ minyak cengkih. Media penyimpanan yang digunakan adalah sekam padi. Serbuk gergaji tidak digunakan sebagai media penyimpanan karena mengandung bahan berbahaya bagi ikan. Jumlah es batu yang digunakan dalam satu wadah penyimpan yaitu $1,8 \mathrm{~kg}$. Penyimpanan ikan dilakukan selama 8 jam dan diamati pada setiap 2 jam. Perlakuan lama penyimpanan ialah $0,2,4,6$ dan 8 jam, dan diulang sebanyak 2 kali.

Parameter yang diamati yaitu waktu kecepatan pingsan (Septiarusli $d k k$, 2012, dan Suwetja, $d k k, 2016)$, waktu penyadaran kembali (Anggriani $d k k, 2014$, dan Suwetja, $d k k, 2016$ ) dan mortalitas ikan (Jailani, 2000, dan Suwetja, $d k k$, 2016). Hasil pengamatan dianalisis menggunakan rancangan acak lengkap.

\section{HASIL DAN PEMBAHASAN}

Pada metode pemingsanan dengan menggunakan suhu $8^{\circ} \mathrm{C}$ dengan lama penyimpanan 0 jam $\left(\mathrm{A}_{1} \mathrm{~B}_{1}\right)$ didapatkan waktu pulih sadar tercepat yaitu 0,3 menit dan terlama diperoleh pada perlakuan dengan metode pemingsanan menggunakan suhu $8^{\circ} \mathrm{C}+$ minyak cengkeh $0,02 \%$ dengan lama penyimpanan 6 jam $\left(\mathrm{A}_{2} \mathrm{~B}_{4}\right)$ yaitu 25,16 menit.

Dari hasil tersebut didapat bahwa penggunaan minyak cengkih $0,02 \%$ dengan lama penyimpanan 6 jam pada metode pemingsanan menghasilkan waktu penyadaran kembali yang lebih lama dibandingkan dengan menggunakan metode pemingsanan tanpa minyak cengkeh. Hal ini disebabkan karena terdapatnya bahan aktif yang terdapat pada sistem peredaran darah dalam tubuh ikan dengan jumlah tertentu yang menyebabkan ikan membutuhkan waktu yang lebih lama untuk kembali ke kondisi normal. Eugenol sebagai zat aktif dalam minyak cengkeh merupakan bahan antiseptik yang dapat melemahkan syaraf dan mengganggu sistem saraf (Hart, 1990).

Dari data waktu penyadaran kembali terlihat bahwa metode pemingsanan dengan menggunakan suhu $8^{\circ} \mathrm{C}$ merupakan metode yang efektif untuk memingsankan ikan dengan lamanya penyimpanan mencapai 6 jam dibandingkan dengan metode pemingsanan menggunakan suhu $8^{\circ} \mathrm{C}+$ minyak cengkih $0,02 \%$.

\section{Hasil Analisis Mortalitas Ikan Mas}

Hasil analisis tingkat mortalitas ikan mas dapat dilihat pada Gambar di bawah ini.

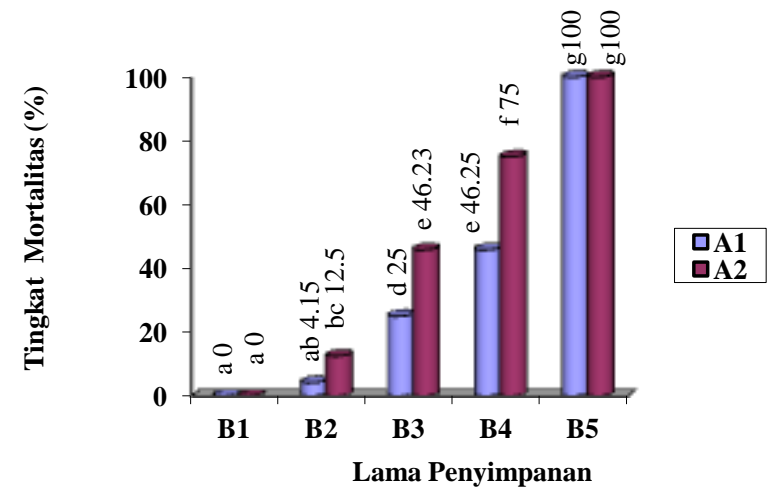

Gambar 1. Histogram hubungan metode pemingsanan dan lama penyimpanan terhadap tingkat mortalitas ikan mas.

Ket.: $\quad \mathrm{A}_{1}$ : Suhu $8^{\circ} \mathrm{C}, \mathrm{A}_{2}$ : suhu $8^{\circ} \mathrm{C}+$ minyak cengkeh $0,02 \%$ $B_{1}: 0$ jam, $B_{2}: 2$ jam, $B_{3}: 4$ jam, $B_{4}: 6$ jam, $B_{5}: 8$ jam

Gambar di atas menunjukkan nilai ratarata tingkat mortalitas ikan mas berkisar antara $0-100 \%$. Hasil analisis sidik ragam pada selang kepercayaan $95 \%$ menunjukkan perlakuan metode pemingsanan, perlakuan lama penyimpanan dan interaksi antara kedua perlakuan tersebut memberikan pengaruh yang nyata terhadap tingkat mortalitas ikan mas $\left(\mathrm{F}_{\text {hit }}\right.$ $>F_{\text {tab }}$ 0,05). Berdasarkan hasil tersebut dilakukan Uji BNT (Beda Nyata Terkecil). Hasil uji lanjut tersebut menunjukkan bahwa perlakuan metode pemingsanan dan perlakuan lama penyimpanan memberikan pengaruh yang nyata begitupun juga dengan interaksi antar kedua perlakuan terhadap tingkat mortalitas ikan mas.

Hasil uji lanjut BNT menunjukkan untuk metode pemingsanan menunjukkan bahwa tingkat mortalitas ikan mas sampai 6 jam penyimpanan dengan metode pemingsanan menggunakan suhu $8^{\circ} \mathrm{C}$ sebesar $46,25 \%$, lebih rendah dibandingkan dengan tingkat mortalitas ikan mas menggunakan suhu $8^{\circ} \mathrm{C}+$ minyak cengkih $0,02 \%$ sebesar $75 \%$. Hal ini menunjukkan bahwa menggunakan suhu $8^{\circ} \mathrm{C}$ sebagai metode pemingsanan lebih baik dibandingkan menngunakan suhu $8^{\circ} \mathrm{C}+$ minyak cengkih $0,02 \%$.

Semakin lama penyimpanan semakin meningkat tingkat kematian pada ikan. Ikan hanya mampu bertahan sampai dengan 6 jam 
penyimpanan. Sampai pada 8 jam penyimpanan, tingkat mortalitas ikan mas $100 \%$ atau tidak ada seekorpun ikan yang berhasil bertahan hidup.

\section{KESIMPULAN}

Dengan media penyimpanan sekam padi dan lama penyimpanan 6 jam dengan metode pemingsanan suhu $8^{\circ} \mathrm{C}$ tanpa minyak cengkih diperoleh tingkat mortalitas optimum yaitu $46 \%$.

\section{DAFTAR PUSTAKA}

Anggraini, D., Taqwa, F. H dan Yulisman. 2014. Mortalitas Benih Ikan Koi (Cyprinus carpio) pada kKetinggian Dasar Media Gabus Ampas Tebu dan Lama Waktu Pengangkutan Yang Berbeda. Jurnal Perikanan dan Kelautan (8): 78-89.

Ferdiansah, 2000. Toksisitas dan Daya Anastesi Minyak Cengkeh (Eugenol Aromaticum) Terhadap Benih Ikan Patin (Pengasius Hypophthalmus) FPIK IPB.

Hart, H. 1990. Kimia Organik Terjemahan Suminar Erlangga, Jakarta.

Jailani. 2000. Mempelajari Pengaruh Penggunaan Pelepah Pisang Sebagai Bahan Pengisi Terhadap Tingkat Kelulusan Hidup Ikan Mas (Cyprinus carpio) [skripsi]. Bogor: Fakultas Perikanan dan Ilmu Kelautan, Institut Pertanian Bogor.

Saskia, Y. Haspeni, E. dan Tutik, K, 2012. Toksisitas dan Kemampuan Anastetik Minyak Cengkih (Eugenol Aromaticum) Terhadap Benih Ikan Pelangi Merah (Glassolepis Nisicus). Jurnal Ilmu Perikanan dan Sumber Daya Perairan.

Septiarusli, I. E., Haetami, K., Mulyani, Y., dan Dono, D. 2012. Potensi Senyawa Metabolit Sekunder Dari Ekstrak Biji Buah Keben (Baringgtonia asiaica) Dalam Proses Anastesi Ikan Kerapu Macan (Ephinephelus fuscoguttatus). Jurnal Perikanan dan Ilmu Kelautan Vol. 3(3): 295-299.

Suwetja, I K., A. Agustin, M.Mengga. 1993. Uji Coba Pengepakan Ikan Mas Hidup Tanpa Media Air. Paper. FPIK UNSRAT.

Suwetja, I K., dan J. Pongoh, 2000. Studi Pemanfaatan Sekam Padi Untuk Transportasi Ikan Mas Hidup dalam Wadah Kotak Kayu Berinsulasi Tanpa Air. Laporan Studi. UNSRAT.

Suwetja, I K., S. Rogi, dan J. Pongoh. 2012. Studi Pemanfaatan Serbuk Gergaji Untuk Transportasi Ikan Mas Hidup Dalam Wadah Tanpa Air. Laporan Studi. UNSRAT.

Wilford, W.A, 1970. Effect of MS 222 on electrolyte and water content in the brain in rainbow trout. US Burean of Sport Fisheries and Wildlife Investigation in Fish Control. 